\title{
Red blood cell distribution width and carotid intima-media thickness in patients with metabolic syndrome
}

\author{
Dongdong Ren ${ }^{1}$, Juan Wang ${ }^{1}$, Hua $\mathrm{Li}^{1}$, Yanyan $\mathrm{Li}^{2}$ and Zhanzhan $\mathrm{Li}^{3^{*}}$
}

\begin{abstract}
Background: To evaluate the relationship between red blood cell distribution width (RDW) and carotid intimamedia thickness (CIMT) in metabolic syndrome (MetS) patients.

Methods: In this study, we analyzed 803 patients with MetS who underwent carotid ultrasonography examination at Henan Province Hospital of Traditional Chinese Medicine from October 2014 to September 2015. Demographic data were collected using a questionnaire. An automatic biochemistry analyzer measured RDW. Pearson correlation coefficient, multivariate linear and logistic regression was used to evaluate the correlation between RDW and CIMT.

Results: Compared with control group, case group had higher RDW level $(P<0.001)$ and CIMT $(P<0.001)$. CIMT was positively related to RDW $(r=0.436, P<0.001)$. Logistic regression indicated that RDW was a predictor of CIMT $\geq 1 \mathrm{~mm}$. Compared with the first quartile, people with third and fourth quartile level gave obvious higher risk of carotid artery atherosclerotic trend $(\mathrm{OR}=1.41,95 \% \mathrm{Cl}: 1.01-197 ; \mathrm{OR}=2.10,95 \% \mathrm{Cl}: 1.30-3.40)$. Using a cutoff point of $13.9 \%$, RDW predicts elevated CIMT with a sensitivity of $62.1 \%$ and a specificity of $70.3 \%$.
\end{abstract}

Conclusion: High RDW is related to the increased CIMT in MetS patients, which highlights the role of RDW in the progression of elevated CIMT in MetS patients.

Keywords: Red blood cell distribution width, Carotid artery atherosclerosis, Metabolic syndrome

\section{Background}

Metabolic syndrome (MetS) is characterized by a cluster of obesity, hypertension, and dyslipidemia-diabetes. It has emerged as a global health issue that affects about $20-30 \%$ of adults in many countries [1-3]. Previous studies suggest that MetS is related to adverse cardiovascular outcomes [4]. Carotid artery atherosclerosis is fprogressive disease caused by thickened carotid intimamedia thickness (CIMT). It has been suggested that elevated CIMT is associated with coronary artery disease, ischemic stroke, and chronic kidney disease, independent of many known influence factors such as age, body mass index, and smoking [5-7]. The clinical symptoms of thickened CIMT are usually not obvious in MetS patients [8]. Therefore, early identification of increased

\footnotetext{
*Correspondence: liche4006@126.com

${ }^{3}$ Department of Oncology, Xiangya Hospital, Central South University, No. 87, Xiangya Road, Changsha, Hunan Province 410008, People's Republic of China Full list of author information is available at the end of the article
}

CIMT is particularly important, which may significantly impact the outcomes.

Red blood cell distribution width (RDW), an index of routine blood examination, reflects the mean corpuscular volume and variability, and is commonly combined with other clinical indices to diagnosis anemia [9]. Lipi and his colleagues reported in 2009 that RDW may be a new inflammatory biomarker [10]. This finding provides a new predictor of potential cardiovascular risks. Recently, many studies suggest that elevated RDW is associated with the increased incidence of cardiovascular events [11-13]. Li et al. found that RDW could predict the early renal function in hypertensive patients with a sensitivity of $76 \%$ and a specificity of $70 \%$ [14]. In parallel with this, a large cohort study with 3529 consecutive patients indicates high RDW ( $\geq 14 \%)$ is independently related to higher rates of MetS [15]. Previous study also indicated a positive relationship between RDW and carotid artery atherosclerosis in patients with ischemic 
stroke [16]. However, there are few studies on the relationship between RDW and CIMT in MetS patients. Since carotid artery atherosclerosis is caused by several inflammatory responses of vascular endothelial injuries, it is inferred that RDW could be involved in the process of carotid artery atherosclerosis. Given the absence of evidence about the association between RDW and CIMT, we think further exploration is needed.

\section{Methods}

\section{Study population}

The present study was based on a cross-sectional design. The study population was selected from our hospital between October 2014 and September 2015. Initially, 915 people were diagnosed with MetS, and those who did not meet the criterion were excluded. Finally, $803 \mathrm{MetS}$ patients were included. The study population was aged from 24 to 54 years old (mean 48.9). More than half of them were males $(65.3 \%)$. The study was approved by the Ethics Committee of Henan Province Hospital of Traditional Chinese Medicine. All participants were informed about the objectives, and signed the written informed the consents. The whole process would have no privacy disclosure.

\section{Criterion for inclusion and exclusion}

Study population must meet the following criteria: clearly diagnosis of MetS. Patients who had history of cardiovascular diseases (ischemic stroke, coronary heart disease, cerebral infarction, hemorrhagic stroke), or severe renal function impairment, gout, tumor, pregnancy, and severe inflammatory diseases were excluded. Those who have diabetic complications, trauma, malignant neoplasms or operations in the past six months were also excluded.

\section{Data collection}

The general information was collected by a questionnaire. An experienced physician measured height, weight, waist circumference (WC), and hip circumference of each patient. Body mass index (BMI) was calculated by the formulation: one's weight in kilograms divided by the square of one's height in meters. The waist to hip ratio (WHR) was also calculated. Blood pressures (SBP: systolic blood pressure, DBP: diastolic blood pressure) were measured three times after $5 \mathrm{~min}$ of rest with at least $15 \mathrm{~s}$ between measurements with the mean taken as the final BP. If a difference of $>5 \mathrm{mmHg}$ was found in any case remeasurement would be done.

Blood for biochemical examinations was drawn from the antecubital vein and examined within $4 \mathrm{~h}$. Blood routine cell counting (red cell, white cell, RDW, platelet, hemoglobin), triglyceride (TG), total cholesterol (TC), high density lipoprotein-cholesterol (HDL-C), low density lipoprotein-cholesterol (LDL-C), and fast plasma glucose (FPG) were measured by an automatic biochemistry analyzer (Beckman Coulter, Inc., Fullerton, CA, USA). Serum creatinine, uric acid, and urea nitrogen were collected by Hitachi Modular System P (Germany). The estimated glomerular filtration rate (eGFR) was calculated by using the formulation [17]: $186 \times[\mathrm{SCr}]^{-1.154} \times[\mathrm{age}]^{-0.203} \times$ $[1.233$ If male $] \times 0.742^{20}$. The eGFR $<60 \mathrm{~mL} / \mathrm{min} / 1.72 \mathrm{~m}^{2}$ indicated the occurrence of chronic kidney disease.

An experienced sonographer performed all carotid ultrasonography by using a machine with a frequency of $11 \mathrm{MHz}$ (ATCUM9, USA). We measured the anterior, lateral and posterior longitudinal carotid arteries. Both sides were done to calculate the CIMT. The elevated CIMT was defined as CIMT $>1 \mathrm{~mm}$ [18].

\section{Diagnostic criteria}

The diagnosis of MetS was based on the criteria recommended by the Chinese Diabetes Society (CDS) Criterion of MetS [19]. Mets was defined as the presence of three or all of the following items: (1) overweight or obesity: BMI $\geq 25.0 \mathrm{~kg} / \mathrm{m}^{2}$; (2) hyperglycemia: $\mathrm{FPG} \geq 6.1 \mathrm{mmol} / \mathrm{L}$ and or $2 \mathrm{~h} \mathrm{PG} \geq 78 \mathrm{mmol} / \mathrm{L}$, and or diagnosis with mellitus diabetes or drug treatment [20] (3) hypertension: SPB and/or DBP $\geq 140 / 90 \mathrm{mmHg}$ [21], and or diagnosed with hypertension or drug treatment. (4) $\mathrm{TG} \geq 1.7 \mathrm{mmol} / \mathrm{L}$, and or HDL-C $<0.9 \mathrm{~mm} / \mathrm{L}$ (male) or $<1.0 \mathrm{mmol} / \mathrm{L}$ (female).

\section{Statistical analysis}

Continuous variables were expressed mean \pm standard deviation or median (min-max) depending on whether data conformed to normal distribution (KolmogorovSmirnov test). Category variables were expressed as percent. Student's-t test, Chi-square test or non-parametric test was chosen according to data distribution. The relationships between CIMT and RDW and other variables were evaluated via Pearson or Spearman's correlation coefficient. Both linear regression and logistic regression were used. Multicollinearity among variables was also assessed by using eigenvalue and condition index before establishment of regression model. All statistical analyses were perfomed on SPSS 18.0 (SPSS inc, USA) with $P<0.05$ as the statistical significance level.

\section{Results}

\section{General characteristics of study subject}

Finally, 803 MetS patients were included, and divided these patients into a case group with CIMT $\geq 1 \mathrm{~mm}$, and a control group with CIMT $<1 \mathrm{~mm}$. The case group has significantly higher RDW level and CIMT compared with the control group (both $P<0.001$ ). The variation coefficient of CIMT is $15.6 \%$. The case group tends to be smoker, and has significantly higher BMI, waist circumference, waist to hip ratio, SBP, triglyceride, LDC-C 
(all $P<0.001)$, DBP $(P=0.007)$, and total cholesterol $(P=0.002)$. The serum creatinine and uric acid levels in the case group are higher than in control group. Besides, the high-sensitivity C-reactive protein (Hs-CRP), red blood cell and hemoglobin levels are all significantly different between the two groups. No significant difference between groups is found in the rest variables. The general characteristics of the study population are shown in Table 1.

\section{Correlation analysis}

The univariate correlation analysis was conducted among CIMT and other variables. Results show CIMT is

Table 1 General characteristics of study population according to the carotid intima-media thickness

\begin{tabular}{|c|c|c|c|}
\hline Parameters & $\begin{array}{l}\text { Control group } \\
(n=516)\end{array}$ & $\begin{array}{l}\text { Case group } \\
(n=287)\end{array}$ & $P$ \\
\hline Age (year) & $48.7 \pm 6.9$ & $49.5 \pm 5.7$ & 0.051 \\
\hline Sex (male, \%) & $345(66.9 \%)$ & $179(62.4 \%)$ & 0.200 \\
\hline Smoking, yes & $178(34.5 \%)$ & $64(22.3 \%)$ & $<0.001$ \\
\hline Drinking history, yes & $88(17.1 \%)$ & $35(12.2 \%)$ & 0.067 \\
\hline Hypertension, yes & $204(39.5 \%)$ & $102(35.5 \%)$ & 0.264 \\
\hline Diabetes mellitus, yes & $76(14.5 \%)$ & $37(12.9 \%)$ & 0.473 \\
\hline Body mass index, $\mathrm{kg} / \mathrm{m}^{2}$ & $25.3 \pm 0.6$ & $25.5 \pm 0.7$ & $<0.001$ \\
\hline Waist circumference, cm & $89.3 \pm 8.1$ & $92.4 \pm 8.2$ & $<0.001$ \\
\hline Waist to hip ratio & $0.85 \pm 0.1$ & $0.88 \pm 0.1$ & $<0.001$ \\
\hline Systolic blood pressure, $\mathrm{mmHg}$ & $143.8 \pm 16.9$ & $148.2 \pm 18.3$ & $<0.001$ \\
\hline Diastolic blood pressure, mmHg & $89.0 \pm 10.4$ & $90.9 \pm 10.5$ & 0.007 \\
\hline Triglyceride, mmol/dL L & $1.5 \pm 0.5$ & $1.9 \pm 0.3$ & $<0.001$ \\
\hline $\mathrm{HDL}-\mathrm{C}, \mathrm{mmol} / \mathrm{dL}$ & $1.1 \pm 0.1$ & $1.0 \pm 0.2$ & 0.500 \\
\hline LDL-C, mmol/dL & $2.7 \pm 0.4$ & $3.0 \pm 0.5$ & $<0.001$ \\
\hline Total cholesterol, mmol/dL & $4.7 \pm 0.4$ & $5.2 \pm 3.4$ & 0.002 \\
\hline Fasting plasma glucose, $\mathrm{mmol} / \mathrm{dL}$ & $6.7 \pm 1.65$ & $6.8 \pm 2.6$ & 0.278 \\
\hline $\mathrm{HbA1c}(\%)$ & $6.2 \pm 1.3$ & $6.4 \pm 1.9$ & 0.056 \\
\hline Serum creatinine, $\mathrm{mmol} / \mathrm{dL}$ & $77.8 \pm 3.2$ & $79.3 \pm 3.3$ & $<0.001$ \\
\hline Serum uric acid, $\mu \mathrm{mol} / \mathrm{L}$ & $323.8 \pm 115.2$ & $354.2 \pm 125.8$ & 0.003 \\
\hline eGFR, (mL/min/1.72 m²) & $72.8 \pm 35.5$ & $95.5 \pm 21.3$ & $<0.001$ \\
\hline Blood urea nitrogen, mmol/L & $4.7 \pm 1.1$ & $4.8 \pm 1.1$ & 0.108 \\
\hline $\mathrm{Hs}-\mathrm{CRP}, \mathrm{mg} / \mathrm{dL}$ & $2.2 \pm 0.5$ & $2.4 \pm 0.8$ & $<0.001$ \\
\hline Red blood cell, $\times 10^{12} / \mathrm{L}$ & $4.5 \pm 0.4$ & $4.4 \pm 0.4$ & $<0.001$ \\
\hline White blood cell, $\times 10^{9} / \mathrm{L}$ & $6.0 \pm 2.4$ & $6.2 \pm 2.5$ & 0.135 \\
\hline Red cell distribution width (\%) & $13.8 \pm 0.4$ & $14.3 \pm 0.3$ & $<0.001$ \\
\hline Blood platelet, $\times 10^{9} / \mathrm{L}$ & $215.6 \pm 74.2$ & $208.3 \pm 54.5$ & 0.056 \\
\hline Hemoglobin,g/L & $145.2 \pm 12.5$ & $150.1 \pm 13.9$ & $<0.001$ \\
\hline CIMT (mm) & $0.9 \pm 0.1$ & $1.2 \pm 0.2$ & $<0.001$ \\
\hline
\end{tabular}

HDL-C high-density lipoprotein cholesterol, $L D L-C$ low-density lipoprotein cholesterol, Hs-CRP high-sensitive C-reactive protein, CIMT carotid intimal-medial thickness positively related to RDW $(r=0.436, P<0.001$, Fig. 1$)$. Similarly, CIMT also has significantly positive relationship with smoking $(r=0.253, P<0.001)$, drinking history ( $r=0.209, P=0.042)$ (Spearman's correlation), waist circumference $(r=0.287, P<0.001)$, SBP $(r=0.425$, $P=0.025)$, triglyceride $(r=0.225, P=0.016)$, LDL-C ( $r=0.125, P=0.035)$, serum uric acid $(r=0.254, P<0.001)$, blood platelet $(r=0.131, P=0.018)$ (Pearson correlation). And the CIMT was negatively associated with hemoglobin $(r=-0.236, P=0.032)$. The main results are shown in Table 2.

\section{Multiple regression analysis}

Also multiple linear and logistic regression analysis were conducted to further explore the possible CIMT and RDW relationship. Both regression models include the following variables: age, sex, smoking, drinking history, hypertension, diabetes mellitus, BMI WC, WHR, SBP, DBP, TG, HDL-C, LDL-C, TC, FPG, HbAlc, serum creatinine, uric acid, BUN, Hs-CRP, red blood cell, white blood cell, blood platelet, RDW, and hemoglobin. The multiple linear regression reveals a positive association between RDW and CIMT $(\beta=0.487, P<0.001)$, independent of potential confounding factors. Specifically, CIMT increases by about $0.5 \mathrm{~mm}$ with one percent change of RDW. The logistic regression indicates that RDW is a predictor of CIMT $\geq 1 \mathrm{~mm}$. Compared with the first quartile, patients in third and fourth quartile have obviously higher risk of carotid artery atherosclerotic $(\mathrm{OR}=1.41,95 \%$ CI:1.01-197; OR $=2.10,95 \% \mathrm{CI}$ : 1.30-3.40). Also a receiver operator characteristic (ROC) curve was used to analyze the predictive values of RDW in detecting thickened CIMT in the Mets population. As shown in Tables 3 and 4, the cutoff value of RDW was $13.9 \%$ with a sensitivity of $62.1 \%$ and a specificity of $70.3 \%$. The Youden index is 0.324 , and the area under ROC curve is 0.698 (95\% CI: 0.657-0.738, Fig. 2).

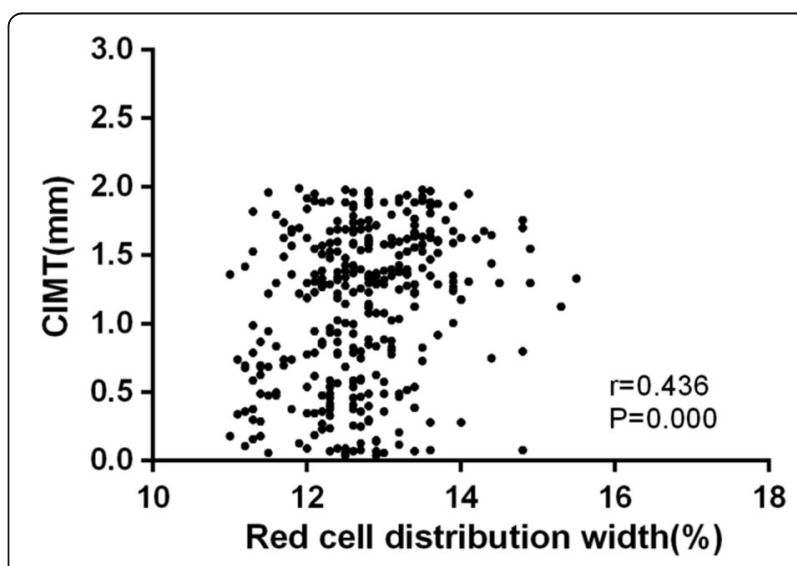

Fig. 1 Scatter plot between RDW and CIMT 
Table 2 Univariate correlation analysis between CIMT and other parameters in patients with MS

\begin{tabular}{|c|c|c|}
\hline Variables & Correlation coefficient & $P$ value \\
\hline Age (year) & 0.029 & 0.562 \\
\hline Sex (male, \%) & 0.038 & 0.396 \\
\hline Smoking, yes & 0.253 & 0.000 \\
\hline Drinking history, yes & 0.209 & 0.042 \\
\hline Hypertension, yes & 0.065 & 0.635 \\
\hline Diabetes mellitus, yes & 0.482 & 0.821 \\
\hline Body mass index, $\mathrm{kg} / \mathrm{m}^{2}$ & 0.078 & 0.125 \\
\hline Waist circumference, cm & 0.287 & 0.000 \\
\hline Waist to hip ratio & 0.097 & 0.051 \\
\hline Systolic blood pressure, $\mathrm{mmHg}$ & 0.425 & 0.025 \\
\hline Diastolic blood pressure, $\mathrm{mmHg}$ & 0.068 & 0.687 \\
\hline Triglyceride, mmol/dL L & 0.225 & 0.016 \\
\hline $\mathrm{HDL}-\mathrm{C}, \mathrm{mmol} / \mathrm{dL}$ & -0.064 & 0.496 \\
\hline $\mathrm{LDL}-\mathrm{C}, \mathrm{mmol} / \mathrm{dL}$ & 0.125 & 0.035 \\
\hline Total cholesterol, mmol/dL & 0.059 & 0.186 \\
\hline Fasting plasma glucose, $\mathrm{mmol} / \mathrm{dL}$ & 0.058 & 0.758 \\
\hline HbA1c (\%) & 0.046 & 0.248 \\
\hline Serum creatinine, $\mathrm{mmol} / \mathrm{dL}$ & 0.047 & 0.293 \\
\hline Serum uric acid, $\mu \mathrm{mol} / \mathrm{L}$ & 0.254 & 0.000 \\
\hline Blood urea nitrogen, $(\mathrm{mmol} / \mathrm{L})$ & 0.064 & 0.355 \\
\hline $\mathrm{Hs}-\mathrm{CRP}, \mathrm{mg} / \mathrm{dL}$ & -0.013 & 0.779 \\
\hline Red blood cell, $\times 10^{12} / \mathrm{L}$ & -0.052 & 0.348 \\
\hline White blood cell, $\times 10^{9} / \mathrm{L}$ & 0.176 & 0.045 \\
\hline Red cell distribution width (\%) & 0.436 & $<0.001$ \\
\hline Blood platelet, $\times 10^{9} / \mathrm{L}$ & 0.131 & 0.018 \\
\hline Hemoglobin,g/L & -0.236 & 0.032 \\
\hline
\end{tabular}

HDL-C high-density lipoprotein cholesterol, $L D L-C$ low-density lipoprotein cholesterol, $\mathrm{Hs}$-CRP high-sensitive C-reactive protein, CIMT carotid intimal-medial thickness

Table 3 Stepwise multiple linear regression analysis for the effect of independent variables on CIMT

\begin{tabular}{lllll}
\hline Variable & Beta $^{\mathrm{a}}$ & S.E. & $t$ & $P$ \\
\hline Constant & -1.822 & 1.151 & 24.09 & $<0.001$ \\
Smoking & 0.150 & 4.572 & 4.07 & 0.001 \\
Waist circumference & 0.125 & 0.632 & 3.76 & 0.004 \\
RDW & 0.487 & 2.044 & 12.69 & $<0.001$ \\
Serum uric acid, & 0.301 & 0.113 & 7.689 & $<0.001$ \\
Triglyceride & 0.115 & 1.562 & 3.94 & 0.012 \\
Systolic blood pressure & 0.193 & 0.140 & 5.25 & $<0.001$ \\
\hline
\end{tabular}

${ }^{\mathrm{a} S t a n d a r d i z e d ~ c o e f f i c i e n t s}$
Table 4 Multiple logistic regression for CIMT in patients with MS

\begin{tabular}{llllll}
\hline Variables & $B$ & S.E. & Wald & $P$ value & OR $(95 \% \mathrm{Cl})$ \\
\hline Smoking & 0.290 & 0.122 & 5.30 & 0.021 & $1.60(1.15-2.22)$ \\
Waist circumference & 0.522 & 0.168 & 9.68 & $<0.001$ & $1.69(1.21-2.34)$ \\
Systolic blood pressure & 0.663 & 0.275 & 5.83 & 0.016 & $1.94(1.13-3.32)$ \\
Triglyceride & 0.530 & 0.208 & 6.47 & 0.011 & $1.70(1.13-2.55)$ \\
Serum uric acid & 0.352 & 0.168 & 4.39 & 0.036 & $1.42(1.02-1.98)$ \\
RDW & & & & & \\
$\quad$ The lowest quartile & & & & & Reference \\
$\quad \begin{array}{l}\text { The second quartile } \\
\text { The third quartile }\end{array}$ & 0.047 & 0.182 & 0.07 & 0.797 & $1.05(0.73-1.50)$ \\
$\quad$ The fourth quartile & 0.744 & 0.170 & 4.16 & 0.041 & $1.41(1.01-1.97)$ \\
\hline
\end{tabular}

\section{Discussion}

Previous studies show that patients with increased CIMT have a higher risk of cardiovascular diseases than the unaffected patients [22, 23]. The elevated RDW is a potential predictor of carotid artery atherosclerosis in patients with ischemic stroke [16]. Early identification is important for such a progressive disease like carotid artery atherosclerosis, and the role of RDW could differ among people settings. The present study finds that patients with CIMT $>1 \mathrm{~mm}$ have higher RDW than those with CIMT $\leq 1 \mathrm{~mm}$, and the elevated RDW is associated with increased CIMT, independent of a number of potential confounding factors. Our findings more strongly support the role of RDW role in the progression of carotid artery atherosclerosis.



Fig. 2 ROC curve was used to analyze the cutoff point of RDW in detecting the increased CIMT 
The relationship between RDW and elevated CIMT may be attributed to two reasons. The first and more important reason could be cytokine-mediated inflammatory response. Since great efforts have been made to explore the mechanism of atherosclerosis in the past several years, it becomes clearer that inflammation is a main reason. As is well known, many inflammatory cytokines play significant roles in the progression of increased CIMT, which results in carotid artery atherosclerosis. As reported, people with increased CIMT have a higher hs-CRP level than the unaffected participants, and the levels of interleukin-6 and tumor necrosis factor- $\alpha$ are also increased $[24,25]$. The increased CIMT is often accompanied by subclinical atherosclerosis. It is suggested that inflammatory arthropathies could be improved by anti-tumor necrosis factor- $\alpha$ therapy in the progression of CIMT [5]. Our study confirms that hsCRP is indeed elevated in patients with CIMT $>1 \mathrm{~mm}$. These findings indicate inflammation widely occurs in patients with elevated CIMT. More importantly, a large cohort study uncovers a strong, graded and positive relationship RDW and hs-CRP [10]. Moreover, erythropoietin concentration is related to aggravated inflammation in non-anemic adults status, and is a negatively associated in anemic population [26]. This finding proves that RDW could predict CIMT in MetS patients. Moreover, RDW in the highest quartile is associated with higher incidence of total stroke and cerebral infarction, and a close relationship between high RDW and IMT, as well as the incidence of carotid plaque, is identified in hypertensive inpatients $[27,28]$. We confirm this relationship in other population settings. This one is different from the previous studies, which show an association between higher RDW and reduced eGFR indicating that lower eGFR could predict higher levels of RDW [14]. However, in the present study, patients with CIMT $<1 \mathrm{~mm}$ have significantly lower eGFR $(72.8 \pm 35.5)$ when compared to the case group with eGFR of $95.5 \pm 21.3 \mathrm{ml} / \mathrm{min} /$ $1.73 \mathrm{~m}^{2}$. This can be explained below. First, previous studies are limited to the hypertension or diabetic population, but the present study has normal renal function. There are differences in life styles such as smoking and drinking. The control group seems to have higher rate of smoking and drinking. The elevated CIMT is a common symptom in the elderly. CIMT consistently increases with age and even tend to affect males [29], while age and gender could both influence RDW [30]. This point further proves the strong relationship between RDW and CIMT. Previous studies tend to attribute these relationships to inflammatory responses, but there is still no accurate and elaborated mechanism. Thus, further investigation is required.

Nevertheless, this study has several limitations. First, it is based on a cross- sectional design, which limits the causal relationship between RDW and CIMT. However, we believe the relationship is probably reasonable after the summarization of previous findings. Second, only MetS patients were included, so the findings should be applied to other people settings with caution. Third, some people had been diagnosed with hypertension or mellitus diabetes, who might be receiving drug treatment. We were inaccessible to this information due to some reasons, and we did not include drug history in the final analysis, which could have some influences on the final results. Finally, we confirmed the possible relationship between RDW and elevated CIMT, but we did not illustrate the accurate mechanism. Thus, further investigations are needed.

\section{Conclusions}

In conclusion, high RDW is related to the increased CIMT in MetS patients, which highlights the role of RDW in the progression of elevated CIMT in MetS patients. As a convenient and inexpensive examination, RDW combined with other clinical examinations could be an effective index for detection of early early carotid artery atherosclerosis. Future studies should focus on the exact mechanism.

\section{Abbreviations \\ BMI: Body mass index; BUN: Blood urea nitrogen; Cl: Confidence interval; CIMT: Carotid intima-media thickness; DBP: Diastolic pressure; eGFR: Estimated glomerular filtration rate; FPG: Fast plasma glucose; HDL-C: High density lipoprotein-cholesterol; Hs-CRP: High-sensitivity C-reactive protein; LDL-C: Low density lipoprotein-cholesterol; MetS: Metabolic syndrome; OR: Odds ratio; RDW: Red cell blood distribution width; SBP: Systolic blood pressure; TC: Total cholesterol; WHR: Waist to hip ratio}

\section{Acknowledgments}

We thank all our colleagues working in the Emergency Department, Henan Province Hospital of Traditional Chinese Medicine.

Funding

Not Application.

Availability of data and materials

The data used for this study is not publicly available. For further information on the data and materials used in this study, please contact the corresponding author

\section{Authors' contributions}

DDR, JW, and LZZ participated in the design of the study and data collection. HL and YYL performed the statistical analysis. DDR, JW, YLC, and ZZL conceived of the study and participated in its design as well as coordination. All authors read and approved the final manuscript.

\section{Competing interests}

The authors declare that they have no competing interests.

Consent for publication

Not applicable.

Ethics approval and consent to participate

The Ethics Committee of Henan Province Hospital of TCM approved the study, and the written informed consent was obtained from all participants in the survey. 


\section{Author details}

'Emergency Department, Henan Province Hospital of Traditional Chinese Medicine, Zhengzhou, Henan Province 450002, People's Republic of China. ${ }^{2}$ Henan Province Hospital of Traditional Chinese Medicine, Zhengzhou, Henan Province 450002, People's Republic of China. ${ }^{3}$ Department of Oncology, Xiangya Hospital, Central South University, No. 87, Xiangya Road, Changsha, Hunan Province 410008, People's Republic of China.

\section{Received: 10 August 2016 Accepted: 20 January 2017}

Published online: 28 January 2017

\section{References}

1. Miller JM, Kaylor MB, Johannsson M, Bay C, Churilla JR. Prevalence of metabolic syndrome and individual criterion in US adolescents: 2001-2010 National Health and Nutrition Examination Survey. Metab Syndr Relat Disord. 2014;12(10):527-32

2. Peer N, Lombard C, Steyn K, Levitt N. High prevalence of metabolic syndrome in the Black population of Cape Town: The Cardiovascular Risk in Black South Africans (CRIBSA) study. Eur J Prev Cardiol. 2015;22(8):1036-42.

3. Lovre D, Mauvais-Jarvis F. Trends in prevalence of the metabolic syndrome. JAMA. 2015;314(9):950

4. Klein BE, Klein R, Lee KE. Components of the metabolic syndrome and risk of cardiovascular disease and diabetes in Beaver Dam. Diabetes Care. 2002:25(10):1790-4.

5. Han QF, Wu L, Li T, Meng XY, Yao HC. There is a link between carotid intima media thickness and coronary artery disease: It might be inflammation. Int J Cardiol. 2016;203:1144-5.

6. Waje-Andreassen $U$, Naess $H$, Thomassen L, Maroy TH, Mazengia KY, Eide GE, Vedeler CA. Biomarkers related to carotid intima-media thickness and plaques in long-term survivors of ischemic stroke. Transl Stroke Res. 2015:6(4):276-83.

7. Hinderliter A, Padilla RL, Gillespie BW, Levin NW, Kotanko P, Kiser M, Finkelstein F, Rajagopalan S, Saran R. Association of carotid intima-media thickness with cardiovascular risk factors and patient outcomes in advanced chronic kidney disease: the RRI-CKD study. Clin Nephrol. 2015:84(1):10-20.

8. Greenland P, Alpert JS, Beller GA, Benjamin EJ, Budoff MJ, Fayad ZA, Foster E, Hlatky MA, Hodgson JM, Kushner FG, et al. 2010 ACCF/AHA guideline for assessment of cardiovascular risk in asymptomatic adults: executive summary: a report of the American College of Cardiology Foundation/American Heart Association Task Force on Practice Guidelines. Circulation. 2010;122(25):2748-64.

9. Evans TC, Jehle D. The red blood cell distribution width. J Emerg Med. 1991;9 Suppl 1:71-4.

10. Lippi G, Targher G, Montagnana M, Salvagno GL, Zoppini G, Guidi GC. Relation between red blood cell distribution width and inflammatory biomarkers in a large cohort of unselected outpatients. Arch Pathol Lab Med. 2009;133(4):628-32.

11. Nishizaki Y, Daida H. Red blood cell distribution width for heart failure. Intern Med. 2013;52(3):417

12. Nunez J, Nunez E, Rizopoulos D, Minana G, Bodi V, Bondanza L, Husser O, Merlos P, Santas E, Pascual-Figal D, et al. Red blood cell distribution width is longitudinally associated with mortality and anemia in heart failure patients. Circ J. 2014:78(2):410-8

13. Patel KV, Ferrucci L, Ershler WB, Longo DL, Guralnik JM. Red blood cell distribution width and the risk of death in middle-aged and older adults. Arch Intern Med. 2009;169(5):515-23.

14. Li ZZ, Chen L, Yuan H, Zhou T, Kuang ZM. Relationship between red blood cell distribution width and early-stage renal function damage in patients with essential hypertension. J Hypertens. 2014:32(12):2450-6.

15. Laufer PM, Havakuk O, Finkelstein A, Halkin A, Revivo M, Elbaz M, Herz I, Keren G, Banai S, Arbel Y. High red blood cell distribution width is associated with the metabolic syndrome. Clin Hemorheol Microcirc. 2015;63(1):35-43.

16. Jia H, Li H, Zhang Y, Li C, Hu Y, Xia C. Association between red blood cell distribution width (RDW) and carotid artery atherosclerosis (CAS) in patients with primary ischemic stroke. Arch Gerontol Geriatr. 2015:61(1):72-5.

17. Myers GL, Miller WG, Coresh J, Fleming J, Greenberg N, Greene T, Hostetter T, Levey AS, Panteghini M, Welch M, et al. Recommendations for improving serum creatinine measurement: a report from the Laboratory Working Group of the National Kidney Disease Education Program. Clin Chem. 2006:52(1):5-18.

18. Carroll BA. Carotid sonography. Radiology. 1991;178(2):303-13.
19. Kuroki Y, Kanauchi K, Kanauchi M. Adherence index to the American Heart Association Diet and Lifestyle Recommendation is associated with the metabolic syndrome in Japanese male workers. Eur J Intern Med. 2012;23(8):e199-203.

20. Seino $Y$, Nanjo K, Tajima N, Kadowaki T, Kashiwagi A, Araki E, Ito C, Inagaki $N$, Iwamoto $Y$, Kasuga $M$, et al. Report of the committee on the classification and diagnostic criteria of diabetes mellitus. J Diabetes Investig. 2010;1(5):212-28.

21. Chobanian AV, Bakris GL, Black HR, Cushman WC, Green LA, Izzo JJ, Jones DW, Materson BJ, Oparil S, Wright JJ, et al. Seventh report of the Joint National Committee on Prevention, Detection, Evaluation, and Treatment of High Blood Pressure. Hypertension. 2003;42(6):1206-52.

22. Mookadam F, Tanasunont W, Jalal U, Mookadam M, Wilansky S. Carotid intimamedia thickness and cardiovascular risk. Future Cardiol. 2011;7(2):173-82.

23. Vercoza AM, Baldisserotto M, de Los SC, Poli-de-Figueiredo CE, D'Avila DO. Cardiovascular risk factors and carotid intima-media thickness in asymptomatic children. Pediatr Cardiol. 2009;30(8):1055-60.

24. Kawase IK, Kokubo Y, Yokota C, Hida E, Miyata T, Toyoda K, Matsumoto M, Minematsu K, Miyamoto Y. Effect of plasma fibrinogen, high-sensitive Creactive protein, and cigarette smoking on carotid atherosclerosis: the Suita study. J Stroke Cerebrovasc Dis. 2015;24(10):2385-9.

25. Vazquez-Del MM, Nunez-Atahualpa L, Figueroa-Sanchez M, Gomez-Banuelos E Rocha-Munoz AD, Martin-Marquez BT, Corona-Sanchez EG, Martinez-Garcia EA, Macias-Reyes H, Gonzalez-Lopez L, et al. Serum levels of anticyclic citrullinated peptide antibodies, interleukin-6, tumor necrosis factor-alpha, and C-reactive protein are associated with increased carotid intima-media thickness: a crosssectional analysis of a cohort of rheumatoid arthritis patients without cardiovascular risk factors. Biomed Res Int. 2015;2015:342649.

26. Ferrucci L, Guralnik JM, Woodman RC, Bandinelli S, Lauretani F, Corsi AM, Chaves $\mathrm{PH}$, Ershler WB, Longo DL. Proinflammatory state and circulating erythropoietin in persons with and without anemia. Am J Med. 2005;118(11):1288

27. Soderholm M, Borne $Y$, Hedblad B, Persson M, Engstrom G. Red cell distribution width in relation to incidence of stroke and carotid atherosclerosis: a population-based cohort study. PLoS One. 2015;10(5):e124957.

28. Wen Y. High red blood cell distribution width is closely associated with risk of carotid artery atherosclerosis in patients with hypertension. Exp Clin Cardiol. 2010;15(3):37-40

29. Su TC, Chien KL, Jeng JS, Chen MF, Hsu HC, Torng PL, Sung FC, Lee YT. Age- and gender-associated determinants of carotid intima-media thickness: a community-based study. J Atheroscler Thromb. 2012;19(9):872-80.

30. Lippi G, Salvagno GL, Guidi GC. Red blood cell distribution width is significantly associated with aging and gender. Clin Chem Lab Med. 2014:52(9):e197-9.

\section{Submit your next manuscript to BioMed Central and we will help you at every step:}

- We accept pre-submission inquiries

- Our selector tool helps you to find the most relevant journal

- We provide round the clock customer support

- Convenient online submission

- Thorough peer review

- Inclusion in PubMed and all major indexing services

- Maximum visibility for your research

Submit your manuscript at www.biomedcentral.com/submit
C) Biomed Central 